Canadian University Music Review

Revue de musique des universités canadiennes

\title{
Factors of Musical Perception: Three Points of View
}

Ireneus Zuk, David Keane et Lola Cuddy

Numéro 3, 1982

URI : https://id.erudit.org/iderudit/1013830ar

DOI : https://doi.org/10.7202/1013830ar

Aller au sommaire du numéro

Éditeur(s)

Canadian University Music Society / Société de musique des universités

canadiennes

ISSN

0710-0353 (imprimé)

2291-2436 (numérique)

Découvrir la revue

Citer cet article

Zuk, I., Keane, D. \& Cuddy, L. (1982). Factors of Musical Perception: Three Points of View. Canadian University Music Review / Revue de musique des universités canadiennes, (3), 102-122. https://doi.org/10.7202/1013830ar

All Rights Reserved (C Canadian University Music Society / Société de musique des universités canadiennes, 1982
Ce document est protégé par la loi sur le droit d'auteur. L'utilisation des services d'Érudit (y compris la reproduction) est assujettie à sa politique d'utilisation que vous pouvez consulter en ligne.

https://apropos.erudit.org/fr/usagers/politique-dutilisation/ 


\section{FACTORS OF MUSICAL PERCEPTION: THREE POINTS OF VIEW The performer - Ireneus Zuk The composer/theorist - David Keane The psychologist - Lola Cuddy}

A performance of two markedly constrasting works, Pictures at an Exhibition by Modeste Moussorgsky and Klavierstück IX by Karlheinz Stockhausen, was given by pianist Ireneus Zuk. The concert was intended to provide music at a time when the questions about the nature of musical experience were in the foreground of the thoughts of those present. Following the performance, Zuk compared the distinctive natures of the pieces, and outlined those aspects which he felt were primary to the listener's experience. Zuk described how these aspects are taken into consideration when the pieces are prepared for performance. David Keane described factors of musical perception which he, as a composer, felt determined his response. Finally, Lola Cuddy examined the evening's musical experience from the standpoint of her work in experimental psychology. The views, which were prepared independently, address a diverse array of problems and issues. There is, however, a common core promising that one day, indeed, people from different disciplines will be able to talk to each other about musical perception with considerable cogency and congeniality.

\section{The Performer - Ireneus Zuk}

In discussing the two works on tonight's program, I shall speak of two aspects: (1) some essential differences between the two works and how they might be perceived by the listener; and (2) possible differences in approach to the preparation of these 
works for performance, with a view to facilitating the listener's perception. The works are almost at opposite ends of the spectrum of musical possibilities: on the one hand, we have Moussorgsky's highly programmatic Pictures; on the other hand, the absolute music of Stockhausen.

First, let us consider the listener's perceptions. It may seem at first that the programmatic piece has the advantage here. Since it does have a program or set of images connected with it, the listener may follow the music by imagining the titles of individual sections or by thinking of the drawings by which the work was inspired. However, the work that Moussorgsky produced is of such high quality that it is equally effective without a program. I like to judge his work, therefore, by what listeners imagine and how they react without their knowing that there is a program connected with it. The reaction to the musical content alone is invariably positive. It is also interesting to note that some passages which cannot help but elicit a definite image in my mind derived from looking at the original drawings, from writings about the work, from others' suggestions, or from my own imagination, often evoke totally different images in the minds of a person listening without preconception.

In the Stockhausen there are no concrete images to help the listener. Even the title, Klavierstück IX, provides no more information than the medium of performance. Instead of images, the listener perceives patterns: patterns of sounds, rhythm, harmony, etc. The sum total of the patterns sets up an aural environment of a specific character and it is this which is perceived by the listener. The listener's enjoyment comes primarily from the perception of this environment. Additional enjoyment may come from the recognition of specific patterns.

In the Stockhausen, the initial chord may act as a recognizable feature through its reiteration, prolongation, and ornamentation in the work. While patterns also exist in the Moussorgsky, they are far simpler. Perhaps they are more familiar to our ears, and it is this familiarity which may make them more readily comprehensible. In the Moussorgsky, the most readily heard melodic pattern is the promenade theme which acts as a Leitmotif, connecting the various sections. Even though it is sometimes obscured by harmony, counterpoint, tremolo, or texture, it is perceived according to the degree of familiarity and/or aural recognition ability of the listener. The stimulus of each appearance of this theme may provide some pleasure to the listener and 
also help to keep the piece moving forward in his mind. In the Pictures there is also a relatively easily recognizable structure, more regular rhythmic patterns, traditional harmonic language, and other features associated with music of that time. While Moussorgsky explores sound possibilities in expressing his concept of the pictures, essentially he breaks no new ground - there are no new procedures. Stockhausen on the other hand, is exploring new possibilities and experimenting with ways of achieving these.

Departures from expected patterns are significant in that they add variety and interest by avoiding predictability (clichés), or regularity (boredom). The breaking or absence of a pattern may also serve as a point of recognition, particularly in the Stockhausen. In his book, The Works of Stockhausen, Robin Maconie has commented: "... a strange tension arises out of the contrast between instrumental reverberation time and the composer's use of a greatly extended scale of duration values. The listener's reaction to a seemingly artificial distension of musical time is paradoxically a sense of heightened expectation ..." (1976:147).

Having touched briefly on what I perceive to be some of the main differences between the two works (in terms of aural perception), I should now like to address my second point and compare the manner of preparation to bring out these differences to facilitate the comprehension.

The performer is faced with essentially the same kinds of tasks in the two works. For this reason I do not believe that preparation is very different for the Moussorgsky than for the Stockhausen. There are, of course, elements of varying difficulties and different technical problems in achieving the desired results. The performer's primary consideration should be to portray the work as the composer intended. For that reason the creator's intention must be clear in the performer's mind from the initial stages right through to the performance.

Even background information such as the purpose of composition can be helpful. The Pictures, for example, was written as a tribute to Victor Hartmann. After Victor Hartmann's death in 1873, Moussorgsky attended a retrospective exhibition of the artist's works and was moved to compose the monumental piano work as a tribute to his late friend: hence the title Pictures from an Exhibition. Some of the original drawings which inspired the work still exist and provide a valuable clue for both performer and listener. 
Stockhausen provided us with the following clues in a program note on the occasion of the first performance of Klavierstück IX: "It brings together different forms of musical time: periodicity, and a whole series of degrees of aperiodicity. Rigid, 'monotonous' events are transformed into flexible, 'polytonous' ones; sometimes the two are abruptly juxtaposed, sometimes they intermingle in constantly fresh conjunctions" (quoted in Wörner 1973:36). While Moussorgsky provides us with no program note of that nature, his work is not abstract philosophically, and the titles of the pictures provide clues for both listener and performer. Without the background information about either work as given above, the performer might lose sight of the purpose of their composition. It may then become more difficult to convey the composer's intention.

A structural analysis, however, remains one of the most important tasks of the performer. While structure is not always apparent to the listener, the performer's knowledge of it permits him to convey the work in better proportion and to make it more convincing. The listener feels rather than understands the coherence resulting from a sense of balance and proportion, highlighted by the performer's knowledge of the underlying structure of the aural environment (to which reference was made earlier).

While one can certainly enjoy Bach without any formal study or prior knowledge, a listener's perception of contrapuntal or harmonic patterns (structure) can only add a further dimension to his perception and reinforce his enjoyment. The performer, on the other hand, must be aware of the totality and the details in order to be able to convey the work to listeners of varying degrees of sophistication. As the Moussorgsky is more familiar to most listeners and its structure is more readily perceptible, I shall move on to describe briefly the structure in the Stockhausen.

Klavierstück IX is a work in two distinct episodes: a chordal section in which the basic material is a single chord built of two perfect fourths a semitone apart, and a following section in which the chordal element disintegrates into or is replaced by a linear (melodic) structure. The chord, the basic structural harmonic element, is first of all repeated many times and then sustained and ornamented (active and passive prolongation). "These two types of treatment intercut, overlap, and finally merge, creating ... a fundmentally simple 'pointillist' structure subjected to various kinds of simulated electronic transformation" (Maconie 1976:147). 
The two large episodes are composed of thirty-three smaller sections. There are twenty-four major and nine minor sections underlining a seemingly important ratio of $8: 3$. This ratio is also present in the main speeds of the first section 160:60. 8 and 3 are two numbers in the Fibonacci series. The bar durations in the first section are organized according to this series $(1,2,3,5,8,13$, $21,34, \ldots$ etc.) (see ibid.) It is not necessary for the listener to recognize that the bars are in a Fibonacci relationship. It may, in fact, not be possible to perceive this organization even for an experienced and sophisticated listener. However, it gives coherence to the work, adds a sense of organization for the performer and helps him to feel more "comfortable" in the portrayal of the work. It is my feeling that a really good performance of the work (or any work) is not possible without some form of understanding of the structure, whether acquired or intuitive.

Another important aspect which helps the performer is the knowledge that Stockhausen was concerned with an attempt to serialize all aspects of sound (sound in all parameters). In his book on twentieth-century music, Eric Salzman mentions that Stockhausen's efforts in the early Klavierstücke were not very successful, as the technique and formal ideas overpower the actual materials and some of the combinations and refined distinctions cannot be realized (see 1974:149). However, Stockhausen was able to find a viable vehicle for his attempts at serialization in electronic music. In Klavierstück IX he attempts to apply electronic techniques to piano procedures.

Let us return for a moment to the first section of the work, the repeated chord, its sustaining and ornamentation. The repetition of the opening chord is not unlike "feedback" echo effect; in other places, reverberation is added through gradual depressing of the sustaining pedal:

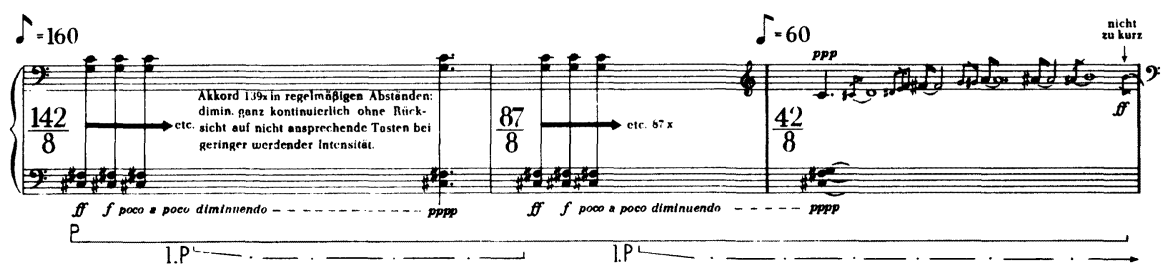

Copyright $\odot 1967$ by Universal Edition (London) Ltd., London.

Reprinted by permission.

Example 1. Stockhausen: Klavierstück IX, mm.1-3. 
In the second line where elements of the chord seem to move out of phase, one is reminded of a tape-loop or tracks moving out of synchronization:

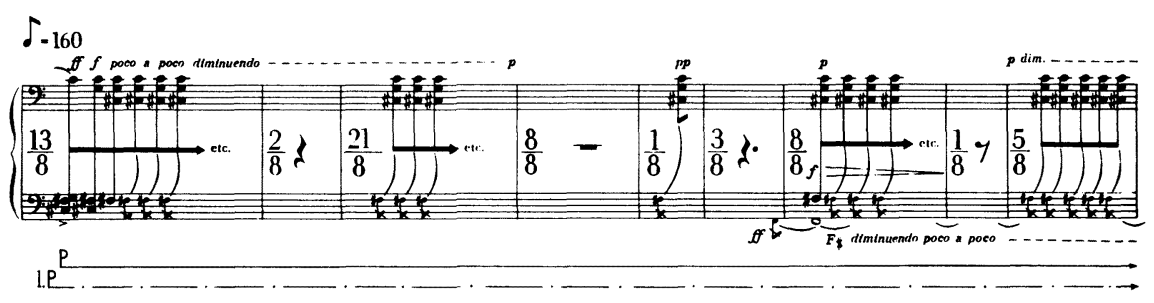

Copyright $\odot 1967$ by Universal Edition (London) Ltd., London. Reprinted by permission.

Example 2. Stockhausen: Klavierstück IX, mm. 4-12.

In a later section one is reminded of the putting together (synthesis) of pre-recorded tape segments. Also in this section reverberation is added through the sympathetic vibration of strings which are sustained by the sostenuto pedal:

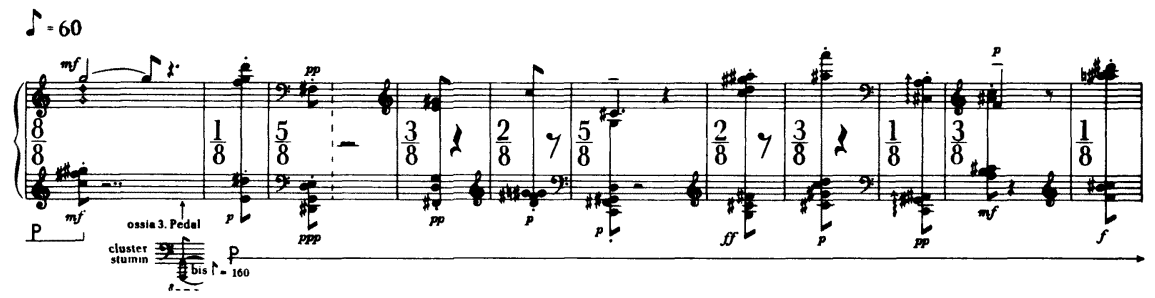

Copyright $\odot 1967$ by Universal Edition (London) Ltd., London. Reprinted by permission.

Example 3. Stockhausen: Klavierstück IX, mm. 94-104.

Being conscious of these intended effects greatly helps the performer in choosing appropriate sound for the various elements in order to imitate the desired electronic effect. Accuracy of execution is important in all works. The notes, rhythm, dynamics, indications, etc. written by the composer must be realized. Of course effects are influenced by the instrument at one's disposal and by the environment in which one is performing. That must also be kept in mind. 
In order to facilitate the perception of important aspects in a given work, the performer must focus on those details which set the work apart from others, and those which add coherence through whatever means the composer intended (such as repetition, juxtaposition, regularity, irregularity, etc). In the Moussorgsky, I attempted the vivid portrayal of the sketches by projecting colors, movement (both rhythmic and within phrases) and energy. In the Stockhausen, I attempted to show the connection between the two large sections and to feel the transformation of the chordal section into the concluding linear disintegration of the chord into the monophonic texture in aperiodic organization.

I should like to suggest that if we were tolisten to both works again (especially the Klavierstück about which most of us had fewer preconceptions or less information or less familiarity) with the additional information we now have - though it is by no means complete - our attitudes and expectations would be affected and as a result we would perceive the works quite differently.

\section{REFERENCES}

MACONIE, R.

1976: The Works of Karlheinz Stockhausen. London: Oxford University Press.

SALZMAN, E.

1974: Twentieth-Century Music: An Introduction. 2nd edition. Englewood Cliffs, N.J.: Prentice-Hall.

WÖRNER, K.H.

1973: Stockhausen: Life and Work. Translated and edited by Bill Hopkins, Berkeley and Los Angeles: University of California Press. 


\section{The Composer/Theorist — David Keane}

There are two principal areas of significance that must be examined if we wish to understand what happens when welisten to music. The first of these is what we call the "music": all of the intentional and incidental structures and forces which comprise the external input to the listener (I am inclined to include the listener's hearing mechanism from the auditory nerve outward as an incidental part of this external system). The second is the listener's involvement with the external input - we might call this the internal input. The interactive nature of the internal and external inputs, as far as the end product is concerned, makes the examination of either area most difficult. That difficulty and the brevity of my remarks forces me to be quitegeneral in treating the two works in question.

I must first confess that despite a deep interest in and commitment to contemporary music and a great respect for the compositional abilities of Karlheinz Stockhausen, my involvement and pleasure was much greater in the Moussorgsky than in the Stockhausen, and I suspect that this represents the response of the great majority of general listeners. Perhaps the most obvious point to be made is that most of us have heard the Moussorgsky more often and that Moussorgsky's idiom is one with which we have far greater experience. It is only natural that our involvement is greater in the Moussorgsky and I think it is reasonable to assume that the greater our active involvement the more pleasure, in one form or another, we derive from the experience.

As a composer, however, my principal interest lies in the nature of the external input rather than the listener's previous experience (a part of the internal input). To be sure, a composer must consider both to a considerable extent but the composer has no control over the internal input whereas he has partial control over the external input.

I have elsewhere (Keane 1982) described in detail the strategies with which the composer attempts to capture and hold the attention of his listeners. But briefly let me say that I see at least 
two levels of involvement for the listener; the first is active and takes place in the conscious mind where the listener engages in recall, prediction, comparison, discovery, etc.; the second is passive and takes place in the subconscious. Whereas the listener is involved in an essentially total awareness of "now" in the subconscious, the awareness in the conscious is rather superficial in the sense that only a few gross features of the experience are actually examined. However, the great strength of the conscious is its ability to handle analytical processes which allow the listener to engage in the past, present, and future of a piece of music. It is this multi-level involvement which is an important source of the pleasure we derive from music listening.

Regardless of the listener's attitude toward the music, I suspect that his subconscious experience of it will be much the same (this is not without qualification, however). It is the conscious level that varies a great deal - the listener's response may range from excitement and total environment to shutting out the music and concentrating on something else entirely. I believe the success of the composer lies primarily with his ability to hold the conscious attention of his listener. This not only requires means to engage the listener's analytical processes but also means to penetrate the listener's potentially wandering attention and return him to the music - the means to make the listener listen. Of course the listener must have a frame of mind disposed to listensympathetic, one might say - or else the means the composer employs to penetrate the wandering conscious prove to be merely an annoyance.

Program music has remained popular for some time because it aids in creating a sympathetic frame of mind. While program music really says nothing about the nature of the extramusical entities, extramusical considerations can provide a context so that the listener is aimed in a sympathetic direction even before the music has begun. The title provides a general context "Ballet of the Unhatched Chicks in their Shells" - and the music provides the detail, color, and richness of the image and the strengthened image reflects back on to the music, giving the listener a greater level of involvement. One need not actually picture chicks dancing in their shells to have the experience heightened. Purely the generalized concept of a specific context is sufficient for the reflected reinforcement to take place.

But of course it takes a great deal more than a program to make a piece of music successful. "Two Polish Jews" is the 
weakest portion of the Moussorgsky simply because the composer allowed the program to dominate the music. Moussorgsky opens by representing a stereotyped Jew, resplendent in profound ancient-world tradition, by means of equally stereotyped musical cues. The music is weak because it is not really interesting in itself. It is merely a set of clichés which provide a background for the program. We have seen that this works better if the program provides a background for the music.

The second section, which depicts an equally stereotyped person but provides a good deal more fresh musical idiom, is more successful. It also is weak, however, in that the musical structure is rather static. Moussorgsky's emphasis seems to have been again on effect rather than musical impact - the program again overwhelms the music. The third section is a juxtaposition of the two musical characters - perhaps suggesting the two men speaking simultaneously - but here the musical purpose provides an interest in the movement and the musical interest outweights the simple fulfillment of the accoutrements of the program.

Does the lack of a program make the Stockhausen less engaging than the Moussorgsky? For me, certainly not. I find few pieces of music more engaging than the entirely abstract keyboard works of Bach, for example. The program merely enhances musical processes which are the real basis of our engagement. These musical processes fall into two areas: the first is in the simple, pleasurable sensation of the sound itself. I use "pleasurable" advisedly but I do not mean necessarily "pleasing" - pleasure can be derived from discomfort, even pain, if the context is right (I am sure I need not expand on that). The problem with pleasure is that the same stimulus decreases in its pleasurable effect over time as we habituate to it; and the number of immediately pleasurable effects of sound, devoid of context (were such a thing possible), are quite limited. Consequently we must look to the second aspect of musical processes - organization of varying sensations over time. Of course, all experience of sound is necessarily time dependent but I am here distinguishing two aspects of sound experience: that which appears to be uniform (homogeneous) and that which appears to be made up of identifiable component parts. Andre Moles has pointed out:

One of the fundamental characteristics of the human receptor is the existence of a maximum limit to the flow of perceptible information. When this maximum flow is exceeded, the individual selects, with the aid of criteria derived from his 
previous experience, forms from the message presented to him. Forms are abstractions, elementary stages of intelligibility. If these criteria fail him, the individual is overwhelmed, left behind by the originality of the message; he loses interest (1966:12).

A most important characteristic of the process of differentiation is the ability to identify those aspects which are the same. If all aspects of experience are in flux there is little hope of identifying parts of the experience and retaining some remnant in the conscious with which to work. Leonard Meyer says that:

In general, the more alike two successive events are, the more separate and discrete they seem to be, and the stronger the implication that they will be followed by a differentiated event in terms of which they can be grouped. This is so because relationships (such as antecedent consequent or weak beat and accent) can arise only if there is some difference - as well as some similarity - between successive events (1976:718).

I find that in large measure there is a gross, compelling feature of sameness in music which Ilike. And this feature is most frequently a combination of a simple rhythmic figure combined with a general contour. The seminal motifs of numbers 2-5 of the Moussorgsky perhaps illustrate this best. The initial appearance is a combination of distinctive rhythm, contour, coloration, and articulation:
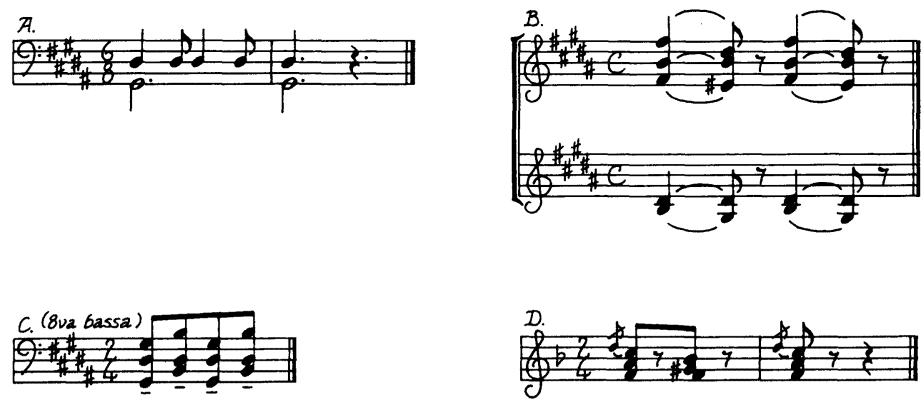

Example 1. Seminal motifs from four movements of Moussorgsky's Pictures at an Exhibition: A. No. 2: Il Vecchio Castello; B. No. 3:

Tuileries; C. No. 4: Bydlo; D. No. 5: Ballet of the Chicks in Their Shells 
Each of these movements is largely a repetition of a seminal motive with sufficient variation to maintain an ongoing freshness while making the listener comfortable with a certain feeling of assurance concerning the makeup of the next bar. We can take certain things more or less for granted in order to concentrate on those foreground elements which seem to be in flux. I describe the ideal piece of music as one which presents exactly the same elements over and over to the unconscious but creates the illusion for the conscious of a constantly fresh series of variants, each the logical, or even the necessary consequences of the one which preceded.

Superimposed on this interlocking texture of repetitions are two major structural elements. One of these is discontinuities. Such points are insurance that we will not simply be lulled into taking too much for granted. If we are not kept alert, the result of a too-consistent structure is much the same as a too-complex structure. Wilson Coker refers to these discontinuities as indices:

We should see that indicating the structure and integration of gestures is the force that indices have. The more dynamic elements - those points that jut out melodically and protrude harmonically or that are conspicuous rhythmically, texturally, and so on - are the ones that define and delineate that to which we are to give the most attention. In short, then, musical indices are created by 1) extremes and 2) sharp contrasts of sonic and rhythmic properties. Within the well defined formal context, these structural cues consist of the musical forms of accent (i.e., tonic, volumetric, ordinal, agogic, dynamic, timbral, articulatory, and textural accent) (1972:92).

Our world progresses primarily in modes that we perceive as either random or patterns which fail to vary'in any significant way (cyclic). Because we can derive no useful information from the random mode and because we take for granted the cyclic mode, once we have identified its basic pattern, we tend to ignore events in both modes. Only events which have some aspects of each mode attract our attention. The progression is characterized by pattern or repetition that gradually alters, or promises to alter, in some way. The most important component is not the beginning or ending point or any of the points along the way, but the movement itself. When a foot race is run, the aspect which is of interest is not, in itself, that a runner attains a certain geographi- 


\section{4}

cal location (often the place he finishes is merely the same place he began) but when he arrives relative to the arrival of the other runners. Also of interest is the course of events along the way which accounts for the relative positions at the conclusion of the race of each of the runners in contrast to their position at the beginning. The moments of excitement arise from changes in relative position and the associated changes in the probable outcome of the race. Without laboring the analogy further, suffice it to say that a piece of music in its most simplified form is progression toward a finishing point, that is, toward a point of rest.

The direction in which we progress is not significant so much as a direction of particular merit as it is merely a place other than the point of rest. The value lies in how interesting the journey away from the point of rest and back again may be. We move away from the point of rest to give us a perspective, to identify that place through the experience of contrasting places. Like the foot race it is not the ultimate arrival but the course of events leading up to the arrival that interests us.

Equal in importance to the movement toward the point of rest is the resistance met along the way. If the composer does no more than take the obvious route, he provides stimulation to the aural perception mechanism of the listener but offers the listener no further involvement with the composition. The listener responds to musical inevitability in the same manner as he responds to other cyclic events - he ignores it. The events of a piece of music must open up distinct possibilities, develop alternatives, meet interference, reveal dimensions of the original possibilities that were always present but not previously observed, and arrive at a place and in a manner which is not only plausible but is seen in retrospect (and preferably only in retrospect) as inevitable (see Keane 1980: 109-10).

Let us compare the opening of the Stockhausen with the opening of "Il Vecchio Castello." In both there is a very obvious progression. In the Stockhausen this is a decrescendo - all other elements are in general constant although the experience is enriched by the necessarily slightly varied durations and attack characteristics owing to human and mechanical imprecision and to the timbral gradations which accompany the progression from loud to soft. In this opening progression there is no significant resistance, however. A kind of resistance is present in the remainder of the piece but deterioration to the point of oblitera- 

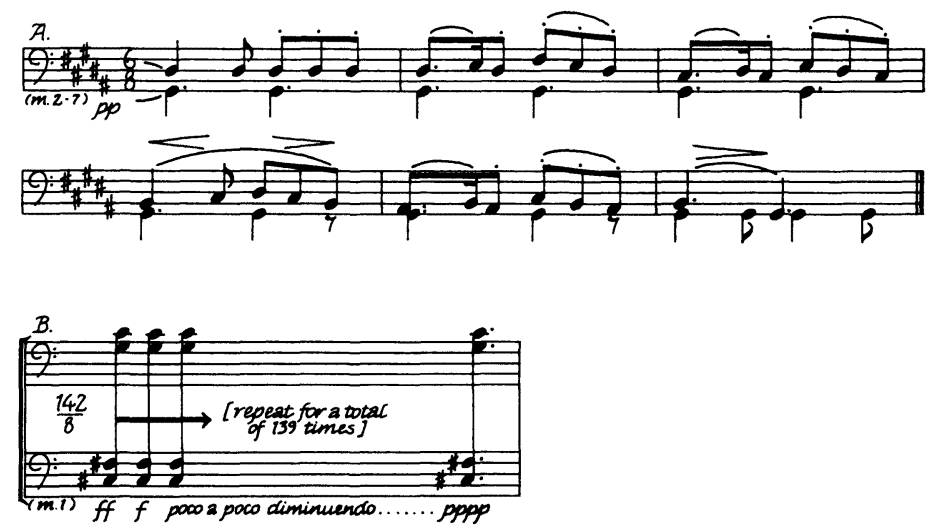

Example 2: Comparison of the opening sequence of A. No. 2; Il Vecchio Castello (from Moussorgsky's Pictures at an Exhibition) and B. Stockhausen's Klavierstück IX

tion would describe the development of this initial figure. The lack of rhythmic or harmonic attractiveness of this opening idea makes the role of progression or development an even more onerous task.

If you charge that I am imposing the expectations of old music on new music, I must respond that one way or another a listener must interact with a piece of music if he is to find it interesting. Regardless of the objectives or aspirations of the composer, the listener will use the only means he has available. I do not believe that these means change as frequently or radically as does musical fashion. Regardless of the idiom, a listener employs more or less the same resources in interacting with a piece of music.

The Moussorgsky relies upon a number of conventions but even without them I think we would find the passage more satisfying than the Stockhausen because there is significant resistance - but resistance which is nevertheless ultimately overcome. We move from the consonance of a P5 (G sharp-D sharp) to a unison (G sharp), a somewhat more pure or less tense version of the P5. The meandering melody, generally working its way down, seems about to move to the tonic with each primary accent but is constantly put off until measure 7 where the tonic is reached belatedly on the secondary accent. For the remainder of the piece we have a series of the same kinds of progressions, becoming more complex harmonically and with overlapping phrases. The tension of the withheld resolution to the tonic on the 
primary accent is actually not resolved until measure $106-$ the final cadence.

In both works there are many levels of progression in each parameter, some complementary, some contrary, creating a complex end result. I have chosen the examples in Example 2 because they are simple and primarily single parameter progressions. These are familiar progressions for which we have a working vocabulary. The majority of the progressions are not so easy to describe but the function is nevertheless of the same nature.

Whether or not we are familiar with the elements of the $G$ sharp minor scales at the beginning of "Il Vecchio Castello" we certainly would be by the end. The pattern is used frequently and consistently and the increments are discrete sufficiently to maintain them in some sort of mental order. Stockhausen himself has pointed out the need to keep interval size to an identifiable minimum (see Cott 1973:95). But in the Stockhausen the sameness of interval size and the lack of an effective tonal focal point (the opening chord construction seems to serve more the function of a color than a tonal reference) deprives the listener of one type of foothold but does not replace it with another.

On observing the score it is not unreasonable to assume that Stockhausen felt that the octave which he fills out chromatically in measure 3 is one of significance with regard to the degree of closure he wished to obtain at this point in the piece. But owing to the chromaticism, the $C$ natural reference is really quite lost by the time we return to it. The closure is much more visible than audible:

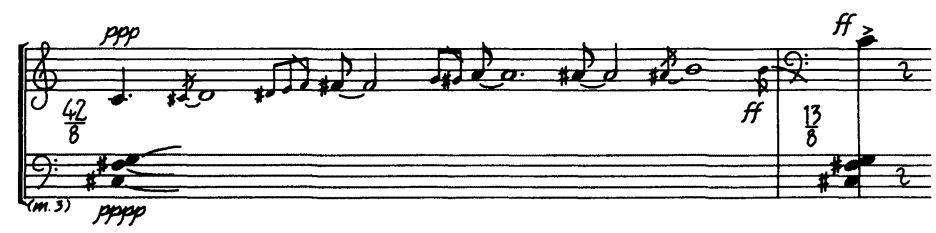

Copyright $\odot 1967$ by Universal Edition (London) Ltd., London. Reprinted by permission.

Example 3: Stockhausen's Klavierstück IX, m. 3.

I fear that the difference in impact of the Moussorgsky and the Stockhausen is the direct result of the increasing amount of abstract formulation, at the expense of actually listening to the 
music, that has taken place in this century. The explanations for music have become increasingly complex and interesting but this has led to a significant degree of decadence in the music itself. Leonard Meyer has suggested: "A musical event implies a number of alternative actualizations. What the composer does is to discover the possibilities implicit in his own musical ideas" (1973:20). It is necessary that the composer makes these discoveries while formulating musical actualizations from abstract constructions. The listener's experience will be only of the musical premise. There is no guarantee at all that the logic abstraction has any connection whatsoever with the experience of music.

\section{REFERENCES}

COKER, W.

1972: Music and Meaning: A Theoretical Introduction to Musical Aesthetics. New York: The Free Press.

COTT, J.

1973: Stockhausen: Conversations with the Composer. New York: Simon and Schuster.

KEANE, D.

1980: Tape Music Composition. London: Oxford University Press.

1982: "A Composer's View: Music, Cognition and Emotion", The Musical Quarterly, LXVIII/3, 324-36.

MEYER, L.

1973: Explaining Music: Essays and Explorations. Berkeley: University of California Press.

1976: "Grammatical Simplicity and Relational Richness: The Trio of Mozart's G Minor Symphony," Critical Inquiry, II/4, 693-761. MOLES, A.

1966: Information Theory and Esthetic Perception. Translated by Joel E. Cohen. Urbana: University of Illinois Press. 


\section{The Psychologist — Lola Cuddy}

Speaking as a psychologist at a music concert puts me in mind of a conference I attended a few years ago at which a very well-known psychologist was giving a paper on psychology and music. To illustrate a point he presented an excerpt from a recording of a Mozart Symphony to the audience and he became so engrossed in the music itself that he forgot that he was on stage and supposed to give a talk. After he finally shook himself and realized where he was, he leaned over to the audience and said, "Humbling experience, isn't it?"

For those of us working in the psychology of music, it is a humbling experience to refer to the real world of music itself. Perhaps it is easy to be intellectually arrogant in front of the rat pressing a lever or in front of some mundane learning task (although we shouldn't be), but the field of music research has a built-in safeguard against arrogance by the presence of great composition and brilliant performance.

The approach of the job of the psychologist, however, is not to analyze the greatness of the music, but to analyze the perceptual and cognitive capabilities of the listener that allow him or her to hear and to appreciate the music. (The interplay between music and the listener, nevertheless, is always there.) Our techniques of study involve simple experiments in which we analyze listeners' responses to sounds and sequences composed according to musical rules. For example, we ask people to listen to brief melodies and try to remember them, to pick out similarities and differences among melodies, to rate melodies for pleasantness or interestingness, and so on (see Cuddy 1982b). Often we find that the principles of auditory organization which our experiments uncover are reflected in the intuitive knowledge base of the composer as postulated by musicological research.

In the next few moments, I would like to suggest several different approaches to the analysis of the musical response. These approaches are derived from the results of our experiments and the experiments of other researchers, from the examination of listeners' protocols, and from interviews with the listeners 
who have participated in our experiments. I suspect that all of the approaches are valid, although each falls somewhat short of being a complete account. In describing these approaches I will make use of terms such as "imagery," "expectancy," and "perceived pattern or structure," thus referring to unobservable events deemed not to be within the domain of psychological study by the early behaviorists but fortunately gaining repute over the past years.

It is indeed possible to specify quite precisely what we mean by these terms by using the language and symbols of geometry, of information theory, or of computing science. We have with us at the symposium a number of acknowledged experts in such applications. However, it is not my intention in this paper to cover technical details but rather to provide a general outline of how we might treat imagery - both acoustic and nonacoustic - and expectancy within an account of how we listened to the pieces just played for us.

The pieces played seemed to me to be ideal examples of the power of music to elicit nonacoustic imaginal responses. The previous speakers have pointed out the specific visual cues that accompany the score of the Moussorgsky piece. In our experiments listeners with musical training often report the use of nonacoustic images to help them remember melodic patterns. Different people report the use of different images but there seem to be fairly well-defined groups: spatial, visual, and motor or kinaesthetic, the last constituting the attempts to feel the vocal or muscular adjustments needed to sing or to play the piece oneself. There is some evidence that auditory contours - patterns of ups and downs in pitch - elicit images of similar visual contours. What seems to be the case is that the report of nonacoustic strategies goes hand in hand with good auditory memory. (I am not inferring cause-and-effect but am referring to correlated events.) However - and this is admittedly speculation at this point - the role of nonacoustic imagery seems to be directed toward focussing the attention upon the acoustic events, not upon helping one sort out and analyze the acoustic events. It helps you to pay attention, shut out distractions, and not to lose your place in the experimental trials. But it doesn't help you, for example, to increase your discrimination between two difficult, unusual, but similar modulations.

It is necessary in the experimental study of musical behavior to concentrate upon the nature of the acoustic events and 
images and their movement in time. Here I would like to comment upon two treatments of the notion of expectancy. One notion emphasizes prediction, arousal, and tension reduction in the face of resolution, the other emphasizes the detection of objective pattern through knowledge of future events. The first notionis an outgrowth of information theory (see Berlyne 1971). It attempts to define optimal information rates, and correlated optimal physiological levels of arousal, for the maximum appreciation of a piece of music. Roughly speaking, we set up a system of "possible events" for a piece of music and as we listen we attempt to predict the ensuing sequence of events. Perfect predictability leads to boredom and unpleasantness; people require a certain degree of unpredictability or a certain number of alternative solutions during the listening process. However, unpredictability induces tension which must be resolved for the final repose of the process. Too much unpredictability leads to too high a level of arousal and a feeling of distaste or unpleasantness (formally referred to as a situation of information overload). This approach to expectancy - which I have treated far from justly and completely - has considerable intuitive appeal. Many listeners feel that contemporary music contains too many unknowns, too many unfamiliar and unpredictable events for enjoyment.

But the approach has run into trouble, and one difficulty that is frequently raised at psychology conferences is simply this: after we have studied and memorized a piece of music, there is no more unpredictability. Why do pieces continue to have different statuses of structure and of desirability for us? If there is no tension-arousal tension-reduction sequence left, why do we continue to listen to, even search out, a particular piece of music?

I think that the answer needs a further clarification of the meaning of expectancy. Expectancy can be seen, not merely as a tension-arousal system, but as the result of the detection of objective pattern in the music and the translation of the pattern into a series of rules or codes (see on this latter point the theoretical developments of Mari Riess Jones 1981). Pieces will differ both in the types and complexities of transformational rules. What we expect is that the structure will be unfolded or the rules realized in real time. The nice thing about the pattern detection approach is that we can study the way in which the listener may revise, embellish, improve the coding of the transformational rules with repeated listening. Additional symmetries and structures become apparent to the listener and the pattern code 
appropriately altered. Thus the pattern detection approach implies that, not only do pieces vary in the richness of structure available, but also that listeners will vary the richness or complexity of the perceptual-cognitive code.

At this point I think the psychologist must approach the score with caution (particularly a computer analysis of the score). It's too easy to detect patterns through a statistical analysis that in fact have no corresponding function in the listening system. I'm here echoing a very important warning from Graham George (1970) which I would paraphrase: "Beware of structures that exist only in the minds of their theorist inventors!" We must always go back to the auditory test of the reality of the structure.

I don't see the three approaches (the use of imagery, prediction, and pattern detection) as mutually exclusive. Listeners may differ in their approaches; perhaps you used different approaches to the two pieces of music. But I think a really exciting challenge for psychology is to take seriously the possibility that we can listen flexibly to a piece of music and perhaps grow and change with repeated listening. 


\section{REFERENCES}

BERLYNE, D.E.

1971: Aesthetics and Psychobiology. New York: Meredith. CUDDY, L.L.

1982a: "From Tone to Melody to Music: Some Directions for a Theory of Musical Cognition," Bulletin of the Council for Research in Music Education, No. 71, 15-29.

1982b: "On Hearing Pattern in Melody," Psychology of Music, X/1, 3-10.

GEORGE, G.

1970: Tonality and Musical Structure. London: Faber and Faber. JONES, M.R.

1981: "Music as a Stimulus for Psychological Motion, Part 1. Some Determinants of Expectancies," Psychomusicology, I/2, 34-51. 